\title{
Is the Post-secondary Classroom a Chilly One for Women? \\ A Review of the Literature
}

DANA WILLIAMS*

\begin{abstract}
A review of the literature on gender bias in the post-secondary classroom reveals that in many cases women students do not participate in class discussions as much as men students. Cause and effect cannot be determined from these studies, but a female teacher and teacher training in sex equitable behaviour are two factors associated with increased female participation. Studies examining student evaluations of teachers reveal that female students rate their female professors higher than their male professors. Research examining post-secondary experiences leading to women's achievement and self-confidence after graduation suggests that attending a woman's college and having female teachers are important. Future research is needed to determine the cause and effect relationship between specific classroom variables on women's classroom participation, satisfaction, and achievement after graduation.
\end{abstract}

\section{RÉSUMÉ}

L'examen de la recherche traitant des différences entre les sexes dans les salles de classe du niveau postsecondaire révèle que, dans bien des cas, les étudiantes interviennent moins que les étudiants dans les discussions. Ces études ne permettent pas de déterminer un rapport de cause à effet, mais semblent indiquer que la présence d'un professeur de sexe féminin, aussi bien qu'une formation des enseignant(e)s visant à obtenir un comportement équitable à l'égard des deux sexes, favorisent la participation des étudiantes. Des études sur l'évaluation des enseignant(e)s par les étudiant(e)s montrent que les étudiantes donnent une meilleure cote aux enseignantes qu' aux enseignants. Les recherches portant sur les expériences du niveau postsecondaire qui encouragent le succès et la confiance en soi chez les diplômées suggèrent l' importance de facteurs tels que les collèges de fermmes et la présence d'enseignantes dans les écoles. Il faudra 
poursuivre les recherches en vue d'établir un rapport de cause à effet entre des variables spécifiques rencontrées dans les salles de classe et qui ont des incidences sur la participation des femmes en classe, leur degré de satisfaction, et leur succès une fois leurs études terminées.

Is the post-secondary classroom climate a chilly one for women? Hall and Sandler (1982), in a report published as part of their work on the Project on the Status and Education of Women, assert that it is. Women and men in the same classroom may have very different experiences. In the majority of cases, this chilly climate is inadvertently communicated to students by their professors. These professors are probably not aware that they are communicating unexamined cultural beliefs that women are not as committed to their education as men, that they are not as smart, and that women's work is not as important as men's work.

Most factors contributing to a chilly climate are subtle; some are overt. A few of the many behaviours of professors listed by Hall and Sandler (1982) which may contribute to a chilly climate include: calling on men students more than women students, asking men more difficult questions, interrupting women students more than men students, making more eye contact with men students when asking questions, using sexist humour or making disparaging remarks about women, using examples where only the man is the professional, using the generic "he" or "man" to represent both men and women, and gearing lecture content to male interests and experiences while neglecting women's interests and experiences.

Hall and Sandler (1982) assert that women's experiences in the classroom may lead to low levels of self-confidence and to a feeling that they do not really belong. Their experiences may lead to a lack of participation in class discussions. Women's experiences may prevent them from seeking help outside of the class. Finally, their experiences may dampen their career aspirations and prevent them from majoring in non-traditional fields.

A large part of Hall and Sandler's (1982) evidence for a chilly classroom environment comes from personal reports from women attending universities. The purpose of this paper is (1) to determine the extent of the experimental evidence for gender bias in the post-secondary classroom, (2) to review research investigating factors which affect the classroom climate of women students, and (3) to discuss recommendations for future research.

\section{EVIDENCE FOR GENDER BIAS}

Studies directly examining gender bias. There is not much research evidence that gender bias in the post-secondary classroom exists. Three studies examine sex differences in classroom interaction patterns, and two studies examine the effects of teacher training in sex equity on student attitudes and classroom interaction patterns. In none of these studies is there any proof that it is the teacher behaviours which are causing the student differences. 
Sex differences in classroom interaction patterns. Karp and Yoels (1976) found that men students were involved in more classroom interactions than women students, especially in male-taught classes. In male-taught classes, men accounted for $75.4 \%$ of the interactions and women $24.6 \%$, while in female-taught classes, men accounted for $57.8 \%$ of the interactions and women $42.2 \%$. The rate of male-female participation did not appear to be a function of overrepresentation of males in male-taught classes because the percentage of male and female students was almost equal in both types of classes.

Sternglanz and Lyberger-Ficek's (1977) findings also indicate more male than female involvement in classroom interactions, especially in male-taught classes. When the teacher initiated an interaction, male students were involved in more classroom interactions than women students in male-taught science and nonscience classes; but the number of male and female interactions was proportionately the same in female-taught nonscience classes. No classroom observations were made in female-taught science classes. In most cases, but especially in male-taught classes, males also attempted to initiate disproportionately more of the interactions with the teacher than did females. They were more likely to raise their hands, make a statement, or ask a question. These researchers also noted that the findings did not seem to be due to an overrepresentation of males in the class because males tended to dominate all classroom interactions whether in the majority or minority.

Unlike the previous researchers, Boersma, Gay, Jones, Morrison, and Remick (1981) did not find any sex differences in student classroom interactions. They found no sex differences in question-asking, number of interactions, who was first to respond to a teacher's initiation, or in who interacted with a teacher just before or after class. Unlike the previous researchers, they did not find more sex-biased classroom interaction patterns in classes taught by males. They, in fact, found the opposite pattern, with males participating more than females in female-taught classes, and females participating more in male-taught than female-taught classes. Females were involved in proportionately more interactions than males in $52 \%$ of male-taught classes and in $29 \%$ of female-taught classes. Boersma et al. (1981) believe that their results are due to better methodology in that they directly matched their male and female professors on class topic, size of class, and class level.

Conflicting results concerning whether teachers differed in their behaviour toward male and female students were found by these researchers. Karp and Yoels (1976) found that male teachers directly questioned male more than female students, while female teachers were equally likely to question male and female students directly. Sternglanz and Lyberger-Ficek (1977), while not examining the number of direct questions to students, found no evidence for differential treatment of students by teachers on other variables. Teachers recognized almost every student's attempt to initiate an interaction and were equally likely to continue an interaction with a male or female student. When comparing teacher behaviour towards male and female students, Boersma et al. (1981) found no sex 
differences in number of interactions - initiating questions, direct questions, number of questions asked in response to students' comments, likelihood of responding to a student, or praise given in response to a student.

Further research is needed to assess what contributes to the sex differences in classroom interaction patterns in some samples and the lack of sex differences in other samples. Much more research is also needed to determine if male and female teachers differ in classroom behaviours not measured, and if these differences contribute to the sex differences in the students. Some variables to assess are: differential eye contact, smiling, and number of interruptions to male and female students. The content of a lecture may affect classroom interactions, with professors who use more female examples and professors who use more positive, high status female examples eliciting more interactions from the women in the class.

However, even if it can be demonstrated that certain teacher behaviours are associated with sex differences in classroom interaction patterns, this does not prove that it is the teacher behaviour which causes the differences. It may be that the sex differences cause the teacher behaviours; i.e., the lack of female response may lead teachers to establish eye contact and smile with males more than females.

The effects of teacher training. Two studies examine the effects of teacher training in sex equity on teacher and student attitudes and classroom interaction patterns. They suggest that training teachers to pay equal attention to male and female students does decrease the sex differences in classroom interaction patterns, but that the introduction of content on women into courses may have detrimental results if not done properly.

Schmitz and Williams (1983) conducted a project to assess how teaching instructors about sex-biased teaching styles and helping them to integrate content on women into their courses affects teacher and student attitudes. A majority of instructors reported positive personal and professional changes as a result of their involvement in the project. Instructors also reported that they modified their language style in the classroom to avoid linguistic bias, paid more attention to nontraditional students in classroom discussions, and tried to place equal demands and expectations on all their students. However, no observational studies were conducted to determine whether teacher behaviours did change or if they affected classroom interaction patterns.

Student reactions were mixed. Approximately half the instructors reported negative, hostile, or defensive reactions from their students, while the other half reported positive, serious, concerned discussions of sex equity issues. The faculty who elicited less hostility and greater sensitivity to issues of sex equity in their students were those who made no mention of the curriculum reform project, who carried on as if the new content was an established part of the course, and who presented the facts with a discussion of competing interpretations.

Long (1986) examined the effects of training college professors in sex equitable and effective interaction skills. An important shortcoming of the previous research 
reviewed is that there is a failure to demonstrate cause and effect. The present study comes closer to demonstrating that teacher behaviour causes sex differences in classroom interactions. There were fewer sex differences in classroom interaction patterns of teachers who were trained in sex equity than in the classrooms of teachers who were not given any training. This suggests that it may be the sex equitable behaviour of the teachers which produces the increased rate of response in the females.

Instructors in the experimental group took part in a Project EFFECT Faculty Development Workshop on Effectiveness and Equity in College Teaching. This was a $21 / 2$ day workshop and one day follow-up session in which instructors were given training, practice, and feedback on sex equitable distribution of attention and precise and effective responses to students' questions and comments. Control group instructors were matched with those in the experimental group on the variables of gender, department, subject taught, and as closely as possible for rank and years of experience. Classes were matched as closely as possible on academic content and class size.

Results indicated proportionately more interactions with males in the control group classroom, with treatment classes near equity, with still a slight bias toward males. In the control classrooms, proportionately more males were salient (involved in at least $1 / 4$ of the classroom interactions), and proportionately more females were silent. The proportion of silent and salient males and females reached equity in treatment classrooms.

While this study is important in that it demonstrated that teachers trained in sex equitable behaviour had more sex equitable classrooms, it is still a quasi experiment since subjects were not randomly assigned to groups. It may be that professors who volunteer to take part in a workshop to eliminate sex-biased classroom interactions are less likely to have those kinds of interactions in their classrooms in the first place. Long (1986) recommends that a true experiment using a pre-post experimental design be conducted to assess cause and effect, to assess whether teacher training causes the sex equitable classroom behaviour.

Anecdotal and questionnaire data. Two studies present anecdotal or questionnaire data on gender bias. One study addresses gender bias in one particular post graduate class, while the other study examines gender bias in a particular department in a college.

Frisbie (1980) examined undergraduate and graduate teacher education students' views about racism and sexism at Georgia Southwestern College. Eight and $7 / 10$ per cent of these students felt that they had been victims of sex discrimination while at Georgia Southwestern College, with more males than females feeling that they had been discriminated against (17\% of males vs $7.3 \%$ of females). Thirty and 26/100 per cent of males and $20.12 \%$ of females indicated they had heard sexist comments by professors in the division of education. Since males were a distinct minority in the teacher education programs, this probably contributed to their experience of gender bias. This study illustrates that gender bias can also exist 
for males when they are in a minority in the classroom. One must also remember that some subtle forms of sex bias may go unrecognized by students and teachers, but at the same time have powerful effects on behaviour and attitude.

Lewis and Simon (1986) discuss their experiences as a female student and male professor, respectively, in a graduate seminar concerning the relationship between language and power. They report that the men in the class monopolized not only the speaking time but the theoretical and social agenda as well. The men students enjoyed a great camaraderie, while the women students were mostly silent spectators. Men spoke at length and were seldom interrupted. When a woman and man began speaking at the same time, the woman always deferred to the man. When a woman did speak, it was as if she had not said anything. What she said was reinterpreted by the men or was attributed in a later discussion by a man to a man.

The professor was aware of the male dominance in the class and unsuccessfully tried to facilitate participation by the women. The women in the class did not participate more fully until they as a group acknowledged to each other the social dynamics of the class and the lack of a feminine perspective taken on the issues that were being discussed. The format of this class was mostly discussion. This paper illustrates the increased difficulties in eliminating gender bias in a discussion format as compared to a lecture format class. In this case, not just the instructor, but all students, must be made aware of the social dynamics of the class. A male instructor, a male majority class, with a discussion format may be especially likely to alienate women students because of a lack of female perspective taken on the issues.

Studies dealing with related issues. The following studies do not directly assess whether gender bias exists in the post-secondary classroom. They do, however, deal with issues concerning the classroom climate for women: the importance of female teachers for female students, the importance of nonsexist language, the importance of female content in textbooks and lectures, and factors which may facilitate greater participation and self-confidence in women students.

Student evaluation of teachers. The following four studies examine student evaluations of their teachers. Studies asking subjects to evaluate a hypothetical male or female teacher are not included.

Elmore and La Pointe (1975) found that female students rated female faculty as significantly more interested in students than male faculty. Male students rated male faculty significantly more interested than female students rated them, and female students rated female faculty significantly more interested than male students rated them.

Bray and Howard (1980) found female students reported significantly more progress in female teachers' classes than in male teachers' classes, and female students reported more progress than male students in female teachers' classes. Androgenous teachers, as measured by the Bem Sex Role Inventory, received higher satisfaction ratings than both masculine and feminine teachers. 
Bennet (1982) found that female instructors are perceived by their students as warmer, more encouraging, less authoritarian, more efficacious, and more potent. Even though students reported receiving more time and personal attention from female instructors, they complained that their female instructors were not available enough. Bennet suggested this might be due to male instructors actively discouraging student contact.

Rosenfeld and Jarrard (1985) found that perceived sexism in college professors makes an important contribution to students' perceptions of classroom climate. Professors in liked classes were perceived as less sexist than those in disliked classes, and male professors were perceived as more sexist than female professors. Perceived low sexist male professors' classes were distinguished from perceived high sexist ones as being higher in supportiveness, innovation, order, and organization and lower in defensiveness. Perceived sexism in female professors did not relate to classroom climate. The authors suggest that this may have been due to the small number of female faculty who were evaluated by the students ( 49 female-taught classes vs 145 male-taught classes), the lower level of perceived sexism of female faculty, or to the possibility that sexism in female professors might be countered by feminine supportive behaviours, such as smiling, which had not been investigated.

Sex biased language. There has been much research on the effects of sex biased language. The following two studies are samples of this research and indicate that the use of the generic "he" is not neutral and can lead to sex role stereotyping.

Moulton, Robinson and Elias (1978) asked male and female college students to make up a story creating a fictional character who fit one of the following two themes, with three conditions across each theme: "In a large co-educational institution, the average student will feel isolated in (his, their, his or her) introductory classes"; OR "Each person knows when (his, their, his or her) appearance is unattractive". Results indicated that using male terms induces people to think of males even when these terms were used in their "neutral" sense. Combining both themes, in the "his" condition, $35 \%$ of the story characters were female, in the "their" condition, $46 \%$ were female, and in the "his or her" condition, $56 \%$ were female.

Briere and Lanktree (1983) showed that the use of the generic "he" could serve to bias subjects to greater sex role stereotyping. Undergraduate male and female students were given one of the three versions of the first paragraph of the 1972 APA "Ethical Standards of Psychologists": (1) the uncorrected version, (2) a version where "he" was replaced by "he or she", and (3) a version where "he" was replaced by "she or he". Subjects then rated psychology on its attractiveness as a future career for men and women as well as their willingness to refer a male friend and a female friend with a psychological problem to a psychologist.

Results indicated that subjects exposed exclusively to male nouns and pronouns rated a career in psychology as less attractive for women than subjects exposed to the two other conditions. Females were most willing to refer a male friend to a 
psychologist under the "she or he" condition and were more willing to refer a male friend under this version than were males. This study indicates that the use of "he or she" and "she or he" in the classroom may have powerful effects on the perceptions of students. If a teacher continually uses the generic "he" in the classroom, female students may be more likely to perceive that the teacher is only referring to males, may be less likely to perceive that the subject matter applies to females, may become less interested and less likely to take part in class discussions, and may become less involved in the academic life on campus.

Sex bias in course and textbook content. Research on the content of current textbooks used in Canadian universities reveals that much subject matter may be exclusively taught from a male point of view. For example, the two most widely used Canadian art history textbooks either omit or gloss over significant female artists and give to the student the impression that Canada's art is Canadian men's art (McInnes-Hayman, 1980). A widely used text in post-secondary English classes, The Norton Anthology of English (4th edition), has no writings by women. A survey done on the 1984-85 Canadian university calendars revealed that in the English courses that listed writers to be studied in their course descriptions, women writers were never more than $1 / 3$ of those mentioned and were usually far fewer (Dagg, 1986). Canadian history textbooks ignore the importance of women or the impact of events on women's lives (Dagg and Thompson, 1988).

The purpose of women's studies courses is to address course content from a female perspective because this has usually not been done in many post-secondary classrooms. However, in Canada, women's studies is underfunded, and there are no tenured professors. Neither has there been any effort in Canadian universities to integrate women's studies into the existing curriculum (Dagg and Thompson, 1988).

A male bias in course and textbook content can contribute to a chilly classroom climate for women. It may lead to a lack of interest in the subject matter, little classroom participation, and to the feeling that women's contributions and ideas are not important. Much more research is needed which directly measures the impact of female oriented course content on women's classroom behaviour and academic goals.

Post-secondary experience leading to women's achievement and selfconfidence after graduation. Three studies have examined learning experiences which lead to women's high achievement and self-confidence after graduation. These studies suggest that attending a woman's college, having female teachers, and having leadership experience at the post-secondary level are the most important factors contributing to a woman's greater self-confidence and achievement after graduation.

Tidball (1973) studied a random sample of 1,500 college graduates cited in Who's Who of American Women from the years 1910 to 1960. These women are twice as likely to have attended a woman's college than a co-educational college. There were almost twice as many women faculty in women's colleges as in 
co-educational institutions. Combining data from the two types of colleges indicated that the number of women faculty and the number of women achievers correlated +.953 . The number of men faculty neither enhanced nor detracted from the output of women achievers. While the growth in the number of male students paralleled the growth in the number of male faculty, women faculty/women student ratios decreased. From 1930 to 1970 this ratio decreased by $48 \%$ in women's colleges and $60 \%$ in co-educational colleges. Also, as the proportion of male students increased in both co-educational and women's colleges, the number of women achievers decreased proportionately. Tidball believes that the presence of male students provides a continual reminder to many women that their main task in college is to find a husband and eventually to become a wife and mother rather than have a career. Also the young woman who has few female teachers suffers from a lack of role models for achievement in the world of work.

It must be remembered, however, that these data are correlational. There may be other factors besides the lack of male students and greater number of female professors which contribute to greater achievement by women in women's colleges. For example, a woman who enrolls in a private woman's college may be higher than average in achievement motivation to begin with. The previously reviewed research on student evaluation of teachers, however, supports the importance of female teachers for female students. Women rate female teachers and their progress in female teachers' classrooms higher than they rate male teachers and their progress in male teachers' classrooms.

Tidball (1976) examined the data from a survey of 42,000 faculty responses to a lengthy questionnaire conducted by the American Council of Education. These faculty were representative of teaching faculty in American institutions of higher education in the beginning of the 1972-73 academic year.

Most men faculty were insensitive to issues that affected women students and which aroused their women colleagues. For example, they were more likely to believe that male students comprehend the material better and to believe that claims of discriminatory practices against women have been greatly exaggerated. When the faculty of single-sex institutions were compared, male faculty believed that male students were more committed to studying than were female students, while female faculty believed that female students were more committed to studying than male students. This again suggests the importance of increasing the number of female teachers for female students. Self-evaluation among men faculty was more positive. Women faculty compared themselves negatively against men in all institutions, the least in women's colleges and the most in co-educational institutions. Tidball concluded again that the climate for women is much more supportive in women's colleges. In co-educational colleges there are few adult same-sex role models. These role models tend to have low self-esteem, and more are in the lower ranks without tenure, with salaries less than their male colleagues at every rank. In women's colleges there are more men in alliance with issues that concern women, there are more women faculty, and they tend to have higher levels of self-esteem.

Astin and Kent (1983) examined longitudinal data to determine which college 
experiences predicted later self-esteem in women graduates. Data sources were from (1) the Co-operative Institutional Research Program (CIRP) which surveyed classes at a representative first year sample of U.S. colleges and universities from 1966 to 1980 , (2) a 1980 follow-up of 50,000 people who had participated in the CIRP survey in 1971, (3) the Higher Education General Information Surveys which collect data on institutional characteristics, and (4) a 1972 survey of faculty members at a representative sample of U.S. institutions conducted by the American Council on Education.

Findings from the CIRP data indicated that first year men from 1966 to 1980 consistently gave themselves higher ratings on academic ability, drive to achieve, and understanding others. The 1980 follow-up data indicated that even though the self-ratings of women improved as they got older, their self-esteem still tended to lag behind men.

The researchers identified a subsample of female leaders from the 1980 follow-up data. These were women who at university had been editor of a campus publication, president of a student organization, or a member of a university or departmental committee. These female leaders had higher levels of self-esteem than other women in 1971, and their self-esteem increased to a greater degree by 1980. Relative to all women, female leaders made substantial gains in academic, leadership, and public-speaking ability. Relative to all women and to male leaders, they made substantial gains in popularity, popularity with the opposite sex, intellectual self-confidence, and social self-confidence. Other experiences which predicted increased self-esteem in women from 1971 to 1980 were attendance at a selective institution rather than a public institution or 4 year college, the presence of liberal arts teaching goals by faculty, and research-oriented faculty who socialized a lot with students.

While the above studies do not examine sex bias in the classroom, they hint at more long-term effects of a chilly classroom atmosphere on women's achievement after graduation. These studies support previously cited findings on the importance of female teachers. These studies are correlational, however. It may be that female teachers produce more successful female students after graduation because they are less likely to have sex-biased interaction patterns or because they provide role models for their students. On the other hand, many other factors besides the sex of the teacher may have produced these results. Correlational data showing the negative relationship between the number of male students in the university and the number of female achievers after graduation is interesting. Sternglanz and Lyberger-Ficek (1976) did not find that there was any difference in classroom interaction patterns in classes where males or females were in the majority. However, the number of classes which had female majorities was very small, and the authors did not indicate the percentage of females in female majority classes. More research is needed to determine directly whether the sex dominance of the class affects classroom interaction patterns, satisfaction, and self-confidence. 


\section{IMPLICATIONS}

There has been increasing concern about sex-biased classroom practices in Canadian universities over the past few years. In spite of this concern, a review of the literature reveals that there is strikingly little research, and strikingly little research in Canada, on whether or not sex-bias exists in the post-secondary classroom, on the factors which facilitate women's classroom participation, or on the kinds of post-secondary classroom experiences which lead to women's greater self-confidence and achievement after graduation.

Research in the following specific areas is needed:

(1) Experimental research is needed to determine whether teacher behaviour affects student classroom interactions. Long (1986) suggests using a pre-post experimental design to compare the classroom interaction patterns of teachers who are trained with those who are not trained in sex equitable behaviour. Experimental research is needed to determine the effects of equitable smiling, eye contact, and interruptions on female class participation. Examination of lecture content is needed, including the effects of female-oriented lecture and textbook content, proportion of female examples and proportion of female professional examples given in lectures, and the effects of the use of "he or she" rather than "he". Hall and Sandler (1982) suggest that women faculty may use a co-operative style; research is needed to determine whether lecturing style influences women's participation.

(2) Although the presence of female instructors is a factor associated with women's greater class participation, satisfaction, and achievement after graduation, it is unclear why this is so. Future research is needed to determine if women professors do have more sex-equitable classroom behaviours.

(3) Research is needed to determine how the sex dominance of a class interacts with sex of instructor to influence classroom participation. Perhaps females are least likely to participate in male majority classes with male instructors, most likely to participate in female majority classes with female instructors, and likely to participate in moderate amounts when sex of instructor and sex dominance of the class are mixed. If this is so, the specific factors which contribute to decreased female participation need to be researched. Perhaps male majority classes with male instructors are most characterized by a combative lecturing style in which female students are frequently interrupted by the teacher and the male students. Perhaps mostly male examples are given, and a female perspective on the issues is never taken.

(4) The impact of gender bias on women in non-traditional majors needs to be researched. Sternglanz and Lyberger-Ficek (1976) investigated classroom interaction patterns in science vs non-science classes but did not investigate student major. Hall and Sandler (1982) suggest that women majoring in non-traditional fields may be especially likely to face difficulties in the classroom because they comprise a distinct minority in a class, they find few female teachers who might serve as role models, and they work with professors who are not accustomed to 
having women students in their classes. One problem encountered in trying to encourage women to enter non-traditional fields is the drop-out rate. In spite of acceptable grades, many women switch to traditionally female majors. More research is needed to determine whether training instructors in traditional male fields in sex-equitable behaviour decreases the likelihood of female students switching to more traditional fields.

(5) Other areas for future study include investigation on how best to train teachers in sex-equitable behaviour, gender bias in graduate school both in and outside the classroom, and gender bias against males in traditionally female majors.

\section{CONCLUSION}

There is not much published research on sex-biased classroom practices in the post-secondary classroom, and not much published Canadian research. However, what has been published does raise many interesting questions.

Many studies have found that women students do not participate as much as men students in the classroom, especially in male-taught classes. Researchers have not investigated what contributes to this lack of participation by females. Possible factors include the lack of female role models and gender biased classroom behaviour on the part of professors: differential smiling, eye contact, interrupting, the number of direct questions posed to students, and the number and kinds of male and female examples given and the lack of a female perspective taken on the subject matter.

Researchers have not investigated how the sex dominance of the class interacts with sex of instructor to influence classroom interaction patterns. If a male-taught class with male students in the majority is least likely to facilitate women students' participation, what are the factors which prevent women from participating? Do instructors in these classes adopt a more combative lecturing style? Are they less likely to give female examples or take a female perspective on the issues?

Researchers have not investigated the impact of gender bias on women in non-traditional majors. Is this a factor leading to many of these women switching to more traditional majors? If instructors in these majors are trained in sexequitable classroom behaviours, will this reduce the drop-out rate?

Training instructors in sex-equitable classroom behaviours facilitates women's classroom participation. However, the inclusion of content on women in courses may sometimes lead to defensive angry reactions on the part of students. More research is needed on how to train instructors in sex-equitable behaviour and on how to include content on women to avoid negative reactions in students.

Studies examining students' perceptions of their teachers indicate the importance of female teachers for female students. Female students perceive female faculty as more interested in them and report more progress.

Research investigating post-secondary experiences leading to women's achievement and self-confidence after graduation indicate the importance of female 
teachers for female students. Women who have attended women's colleges which have a greater proportion of women faculty, are disproportionately represented in Who's Who of American Women from 1910 to 1960. Post-secondary leadership experiences and opportunities to socialize with faculty are factors which contribute to increased levels of self-esteem in women after graduation. More research is needed to examine the long-term effects of sex-equitable classrooms on women's achievement levels and self-confidence after graduation.

Many individuals have expressed concern about removing any barriers in the post-secondary environment that might discourage women from maximizing their potential. A review of the literature on gender bias in the classroom raises many interesting questions. More research is needed on teacher classroom behaviours which facilitate greater female participation in the classroom, which increase female enrolment in non-traditional majors, and which lead to women's high achievement and self-esteem after graduation.

\section{REFERENCES}

Astin, H.S. and Kent, L. (1983). Gender roles in transition: Research and policy implications for higher education. Journal of Higher Education, 54, 309-324.

Bennet, S.K. (1982). Student perceptions of and expectations for male and female instructors: Evidence relating to the questions of gender bias in teaching evaluation. Journal of Educational Psychology, 74, 170-179.

Boersma, P.D., Gay, D., Jones, R.A., Morrison, L., and Remick, H. (1981). Sex differences in college student-teacher interactions: Fact or fantasy? Sex Roles, 7, 775-784.

Bray, J.H. and Howard, G.S. (1980). Interaction of teacher and student sex and sex role orientation and student evaluations of college instruction. Contemporary Educational Psychology, 5, 241-248.

Briere, J. and Lanktree, C. (1983). Sex-role related effects of sex bias in language. Sex Roles, 9, $625-632$.

Dagg, A.I. (1986). The fifty percent solution: Why should women pay for men's culture? Waterloo, Ontario: Otter Press.

Dagg, A.I. and Thompson, P.J. (1988). MisEducation: Women and Canadian universities. Toronto, Ontario: OISE Press.

Elmore, P.B. and La Pointe, K.A. (1975). Effect of teacher sex, student sex, and teacher warmth on the evaluation of college instructors. Journal of Educational Psychology, 67, 368-374.

Frisbie, L.H. (1980). A study of racism and sexism at Georgia Southwestern College. Integrated Education, 18, 61-64.

Hall, R.M. and Sandler, B.R. (1982). The classroom climate: A chilly one for women? Project on the status and education of women, Association of American Colleges.

Karp, D.A. and Yoels, W.C. (1976). The college classroom: Some observations on the meaning of student participation. Sociology and Social Research, 60, 421-439.

Lewis, M. and Simon, R.I. (1986). A discourse not intended for her: Learning and teaching within patriarchy. Harvard Educational Review, 56, 457-471.

Long, J.H. (1986). The effects of teacher sex equity and effectiveness training on classroom interactions at the university level. Unpublished doctoral dissertation.

McInnes-Hayman, S. (1980). Contemporary Canadian women artists: A survey. Ottawa: Status of Women in Canada.

Moulton, J., Robinson, G.M., and Elias, C. (1978). Sex bias in language use: "Neutral" pronouns that aren't. American Psychologist, 33, 1032-1036. 
Rosenfeld, L.B. and Jarrard, M.W. (1985). The effects of perceived sexism in female and male college professors on students' descriptions of classroom climate. Communication Education, $34,205-213$.

Schmitz, B. and Williams, A.S. (1983). Seeking women's equity through curricular reform. Journal of Higher Education, 54, 556-565.

Sternglanz, S.H. and Lyberger-Ficek, S. (1977). Sex differences in student-teacher interactions in the college classroom. Sex Roles, 3, 345-352.

Tidball, M.E. (1973). Perspective on academic women and affirmative action. Educational Record, $54,130-135$.

Tidball, M.E. (1976). Of men and research: The dominant themes in American higher education include neither teaching nor women. Journal of Higher Education, 47, 373-389. 